\title{
Fully endoscopic interlaminar and transforaminal lumbar di- scectomy: clinical results of 857 surgically treated patients
}

\author{
Salih Aydın ${ }^{1}$, Erkut Bolat ${ }^{2}$ \\ ${ }^{1}$ Department of Neurosurgery, Emsey Hospital, Istanbul, Turkey \\ ${ }^{2}$ Department of Biostatistics, Istanbul University Faculty of Medicine, Istanbul, Turkey
}

\begin{abstract}
Minimally invasive surgical techniques are becoming increasingly common in spinal surgery in an attempt to decrease tissue trauma during surgery, which in turn decreases post-operative pain and opioid use.

The aim of this study was to investigate the clinical outcomes of a large group of patients with lumbar disc disease who underwent full endoscopic surgery.

857 patients who underwent fully endoscopic lumbar discectomy were investigated retrospectively. General demographics were evaluated in terms of mean operating time, mean length of hospital stay, mean time to return to work, complications and recurrences. Clinical outcomes were evaluated using visual analogue scale (VAS) for low back and leg pain, and Oswestry Disability Index (ODI) for functional assessment.

The mean follow-up time was 36 months. The operation time ranged from 20 to 65 minutes ( 39 min on average), and there was no measurable intraoperative blood loss. Patients were mobilised on average 3.5 hours after the surgery. The length of hospital stay after the operation was 12-24 hours (18 hours on average). During postoperative follow-up, 19 patients required revision surgery due to recurrence (2.2\%). There was one case of nerve root injury in which the patient recovered well following physical therapy, and 11 cases of paresthesia that gradually improved following 2-6 weeks of rehabilitation and treatment with pregabalin.

All types of lumbar disc herniations are accessible via the full-endoscopic technique. Full-endoscopic discectomy, as a minimally invasive procedure, has the technical advantages of less paraspinal muscle dissection, less tissue trauma, less risk of spinal instability, and minimal blood loss.
\end{abstract}

Key words: endoscopic discectomy, interlaminar, transforaminal, lumbar disc herniation, minimally invasive

(Neurol Neurochir Pol 2019; 53 (6): 492-499)

\section{Introduction}

The gold-standard treatment for lumbar disc herniations has been conventional microsurgical discectomy since Yasargil introduced the microsurgical technique in 1967 [1-3]. Since then, there have been several minimally invasive procedures introduced, such as: nucleotomy, thermal ablation intradiscal electrothermal therapy annuloplasty, nucleoplasty, and chemonucleolysis [4]. In 1997, Smith and Foley introduced the microendoscopic discectomy system as a minimally invasive procedure. It is also known as the tubular discectomy system.
In 1999, a second-generation microendoscopic system called the METRx system (Medtronic Sofamor Danek Inc., Memphis, TN, USA) was introduced. There have been several reports showing favourable results from using the microendoscopic discectomy technique [5].

Today, the full-endoscopic discectomy system allows surgeons to perform discectomy operations using high-quality visualisation as a minimally invasive approach. Modern endoscopic surgery permits surgeons to use endoscopy in various pathologies such as spinal stenosis which has been reported to have favourable results $[6,7]$. 
Full-endoscopic surgical approaches to the spine differ from other minimally invasive techniques because of the unique technical characteristics of the spinal working endoscope. The use of the spinal endoscope furthers the principles of minimally invasive spinal techniques by permitting the surgeon to visualise spinal contents in an expanded-angle field of view $\left(25^{\circ}\right)[6-8]$. This expanded view enhances and facilitates surgical treatment with minimal surgical dissection. The endoscope permits access to all regions of a spinal segment including the subarticular, far-lateral, foraminal and extraforaminal zones. Also, it minimises dural scarring and secondary iatrogenic instability associated with conventional microscopic surgery [9-11].

Two different operative approaches exist: transforaminal (TF) and interlaminar (IL). The transforaminal approach has been the standard procedure for the treatment of lumbar disc herniation (LDH) because of its excellent results in terms of nerve root decompression and low complication rates [12-17]. With the transforaminal approach, the spinal canal is reasonably accessible. However, the osseous perimeter of the foramen and the exiting nerve may limit the working mobility and excision of the dislocated herniated material [18-22]. Especially at the lower lumbar level, a transforaminal approach may be insufficient to access the disc level due to anatomical constraints such as a high iliac crest, narrow neuroforamen, and hypertrophied facet joints $[10,23]$.

The interlaminar approach was proposed by Ruetten et al. to overcome the disadvantages of transforaminal access described above. Excellent outcomes, including significant back and leg pain relief, faster rehabilitation, fewer complications, and minimal soft-tissue trauma, have been demonstrated by Ruetten's serial studies $[8,24]$.

The purpose of our study was to investigate whether endoscopic discectomy has the advantages of a shorter time to return to work, shorter operating time, and favourable clinical outcomes in a particularly large group of patients.

\section{Materials and methods}

857 patients with lumbar disc herniation who underwent full-endoscopic interlaminar/transforaminal discectomy between April 2012 and April 2015 were enrolled in this retrospective study. All patients presented with clinically symptomatic disc herniation and underwent magnetic resonance (MR) imaging. The indication for surgery was defined according to present-day standards based on radicular pain symptoms and existing neurological deficits $[9,25]$. Cases in which the herniated disc was located intraforaminally and extraforaminally or within the spinal canal, and cases with cauda equine syndrome, were included in the study. Transforaminal access was used in the intra- or extraforaminal herniations.

The indications for interlaminar access were herniated discs located mainly inside the spinal canal, which in our experience were difficult to treat using the transforaminal technique.

\section{Operative technique: lateral transforaminal approach}

General anaesthesia was induced prior to surgery in all cases. In the lateral transforaminal approach, surgical access is created with the patient in the prone position while under orthograde two-plane radiological control [20]. Firstly, the location of the skin incision is marked. The needle is advanced to the Kambin triangle under fluoroscopic guidance (Fig. 1). For the L3-4 and L4-5 levels, the dorsal edge of the inferior articular process normally limits the area of ventral entry zone on lateral radiography. A $1.5 \mathrm{~mm}$ atraumatic spinal cannula is inserted via the skin incision directly into the target area. After insertion of a $0.8 \mathrm{~mm}$ lead wire, the cannulated dilator (outer diameter $6.9 \mathrm{~mm}$ ) is pushed in. At this point, the target wire may be removed so that further correction of the position can be made safely with the blunt dilator. A surgical sheath, with bevelled opening and an outer diameter of $7.9 \mathrm{~mm}$, is

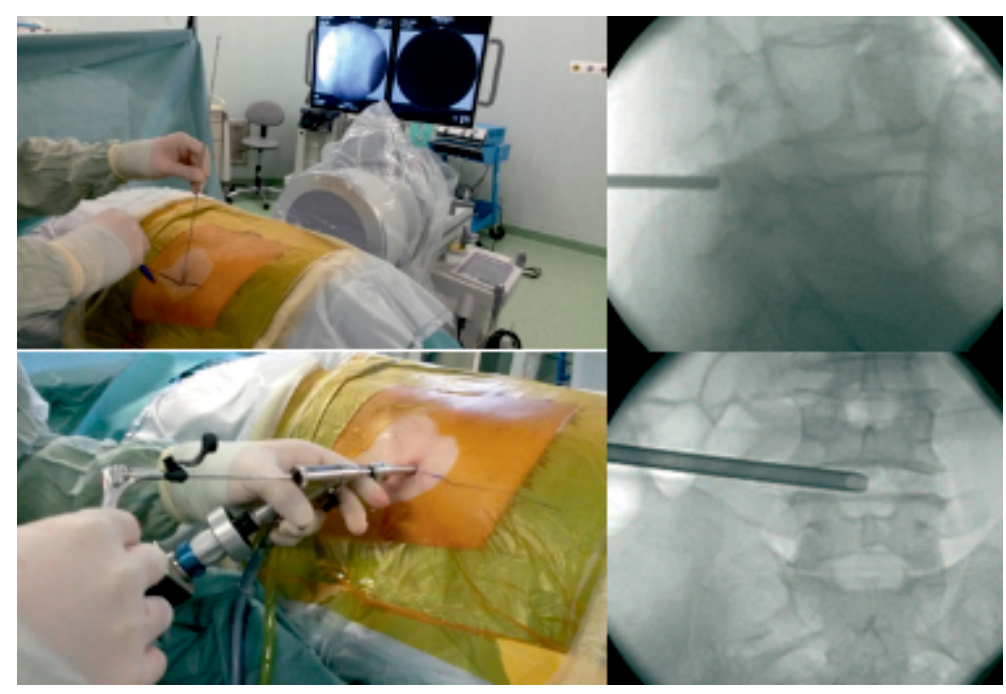

Figure 1. Full-endoscopic transforaminal operation with lateral access and intraoperative C-arm images 


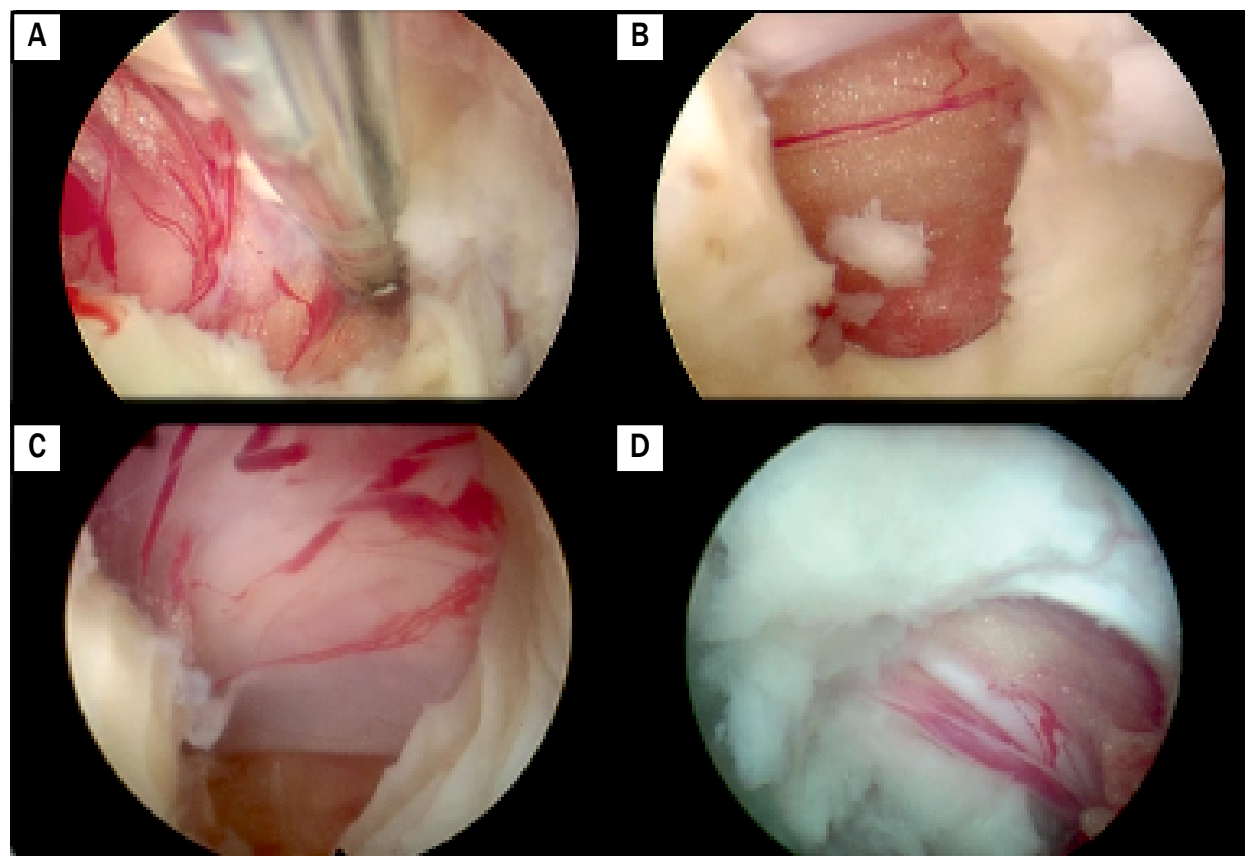

Figure 2. A. Dissecting root using radiofrequency; B. Ligamentum flavum is incised and epidural fat is visible below it; C. Axilla of root and traversing spinal nerve shown on endoscopic view; D. Traversing spinal nerve is shifted centrally through sequestered disc material

placed over the dilator. After the insertion of the endoscope, decompression is performed while maintaining visual control under constant irrigation. If the anatomical diameter of the intervertebral foramen does not permit direct entry into the spinal canal, the opening is expanded by resecting bone using burrs. If the position of the exiting nerve is not clear - for example, cases of intra- or extraforaminal herniations or foraminal stenosis - access is made on the caudal pedicle as a safe zone, and further decompression is performed under visual control.

\section{Operative technique: interlaminar approach}

In the interlaminar approach, surgical access is created with the patient in the prone position while under orthograde two-plane radiological control $[7,8,19,24,26]$. The skin incision is made as medial as possible in the middle of the interlaminar window craniocaudally. A dilator, $6.9 \mathrm{~mm}$ in outer diameter, is inserted bluntly to the lateral edge of the interlaminar window and an operating sheath, with a $7.9 \mathrm{~mm}$ outer diameter and bevelled opening, is directed toward the ligamentum flavum. The procedure is performed under visual control and constant irrigation. A lateral incision of approximately $3-5 \mathrm{~mm}$ is made in the ligamentum flavum; to allow access to the spinal canal, the defect in the ligament is widened further (Fig. 2). The operating sheath can be turned and used as a nerve hook. Mobility within the spinal canal is controlled using a handle on the optics that functions like a joystick. If the anatomical diameter of the interlaminar window does not allow direct access into the spinal canal through the ligamentum flavum, the opening is expanded by resecting bone using a burr (especially at the levels of L4-L5, L3-L4, L2-L3, and L1-L2). In cases involving wide dislocated sequestered fragments, which cannot be completely resected from one level without an extensive bone resection, additional access to the spinal canal can be achieved via the neighbouring level. The nerve root is thus fully decompressed. The nucleus pulposus of the intervertebral disc was subjected to radiofrequency (RF) ablation. No dural sac damage, significant disc fragmentation, or active bleeding occurred, and good relaxation of the nerve root was noted. Next, all instruments were removed, and the skin incision was closed by a single suture. The operation time, bleeding volume, removed disc tissue volume, and intraoperative complications, were recorded for each patient.

\section{Operative instruments}

The rod lens optics has an outer diameter of $6.9 \mathrm{~mm}$ and a usable length of $165 \mathrm{~mm}$ for interlaminar and $205 \mathrm{~mm}$ for transforaminal access. The optics contain an intraendoscopic, eccentric working channel with a diameter of $4.2 \mathrm{~mm}$, inlets for light and rinsing fluid, as well as the optical system itself. The angle of vision is $25^{\circ}$. The working sheaths have a $7.9 \mathrm{~mm}$ outer diameter and a bevelled opening, both of which enable the creation of visual and working fields in an area without a clear, anatomically preformed cavity. The new large intraendoscopic working channel enables sufficient bone resection with burrs or bone punches under visual control. All of the instruments and optics were products supplied by Richard Wolf GmbH [7, 19]. 


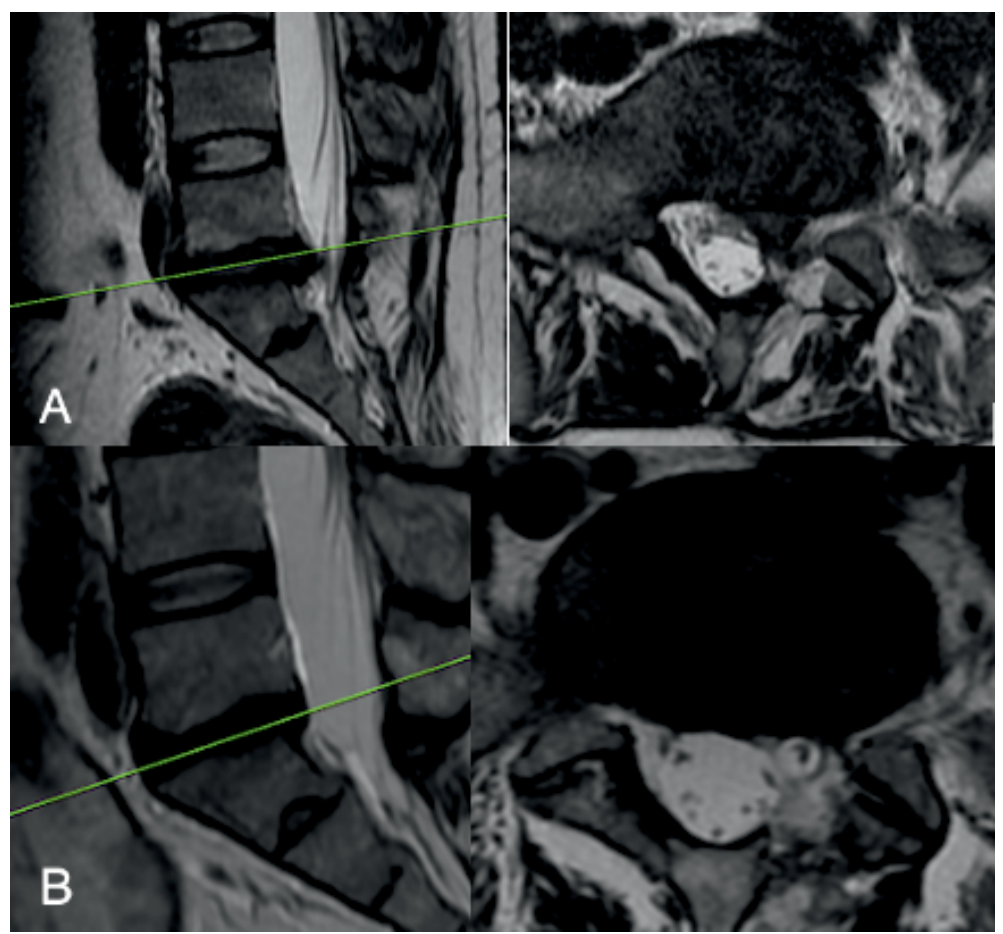

Figure 3. A. Preoperative sagittal and axial MR images of left L5-S1 herniation; B. Postoperative sagittal and axial MR images of left L5-S1 herniation

\section{Follow up}

All of the patients were examined in follow-up appointments at 10 days and one, three, 12 and 36 months after surgery, and patients received a telephone interview or a postal questionnaire four working days prior to their attendance at the outpatient clinic. In addition to general parameters, other information was obtained using the visual analogue scale (VAS) and the Oswestry low-back pain disability questionnaire (ODI) criteria to evaluate the preoperative and postoperative clinical results.

\section{Statistical analysis}

The t-test was used to compare pre- and postoperative VAS and ODI scores. Qualitative characteristics of patients are shown as number (n) and frequency (\%) in Table 1. Quantitative data was presented as mean \pm standard deviation. Chi-square test was performed to test for differences in proportions of categorical variables between groups. Statistical analyses were performed using Statistical Package for the Social Sciences for Windows version 21.0 (IBM SPSS Corp. Armonk, NY, USA). A $p$ value $<0.05$ was considered as statistically significant.

Ethical approval was obtained from the ethical committee, and informed consent was obtained from all participants in the study.

\section{Results}

There were 512 female and 345 male patients, whose ages ranged from 18 to 86 years (mean 47 years). 806 patients
(94\%) underwent an IL procedure and $51(6 \%)$ a TF procedure. Table 1 sets out the demographic characteristics of the patient population.

360 interventions were performed at the L5-S1 level (356 IL and four TF), 421 at L4-5 (389 IL and $32 \mathrm{TF}$ ), 50 at L3-4 (40 IL and $10 \mathrm{TF),} 11$ at L2-3 (eight IL and three TF), and 15 at L1-2 (13 IL and two TF). 827 unilateral procedures were performed and 50 bilateral procedures were conducted in 50 patients with bilateral symptoms. 35 patients underwent two-level surgery due to extensive sequestering (Fig. 3).

The duration of pain was $1.14 \pm 0.6$ days on average. Patients were followed-up for 36 months. 298 patients presented with neurological deficits. 40 patients had undergone previous microscopic surgeries at a different vertebral level. 212 patients with severe pain unresponsive to conservative therapy or with acute paresis underwent surgery immediately.

All of the patients were included in follow up, except three patients who suffered heart attacks within 24 months of the surgery.

As shown in Table 2, mean operating time was significantly shorter in one-level discectomy patients compared to the two-level discectomy group. Mean time to return to work and the number of scope shooting images were significantly lower in the one-level discectomy group compared to the two-level discectomy group as expected. Complications and recurrences were significantly higher in the two-level discectomy patients. 
The preoperative VAS leg score on the affected side was $8.4 \pm 1.2$ and final follow-up VAS leg score improved to 0.6 \pm 0.6 postoperatively $(\mathrm{p}<0.001)$. VAS back score changed from $5.9 \pm 1.6$ to $0.4 \pm 0.2(\mathrm{p}<0.001)$. ODI scores changed from $56.1 \pm 17.7$ to $11.1 \pm 4.4$ postoperatively $(p<0.001)$. Significant improvement was maintained as a means of better VAS and ODI scores one, three and 36 months postoperatively ( $\mathrm{p}<0.001$ ).

The time until the patient was mobilised after surgery was 3.5 hours on average. The length of hospital stay after the operation was 12-24 hours (average 18 hours). The operation time ranged from 20 to 65 minutes (mean 39 minutes).

According to Table 3, there was no significant difference as a means of herniation type for the one-level operations; however, there was significant difference found in the group with two-level disc herniation. In two-level disc herniation patients, extrusion of disc material was seen more frequently.

Table 1. Demographic data for all patients

$\begin{array}{lcc}\text { Demographic information } & \text { Number of patients } & \text { [\%] } \\ \text { Age } & 3 & \\ 0-19 & 43 & 0.4 \\ 20-29 & 183 & 5.00 \\ 30-39 & 305 & 21.4 \\ 40-49 & 173 & 35.6 \\ 50-59 & 109 & 20.2 \\ 60-69 & 41 & 12.7 \\ 70-90 & & 4.8 \\ \text { Gender } & 511 & \\ \text { Female } & 346 & 59.6 \\ \text { Male } & & 40.4 \\ \text { Operation Level } & 822 & \\ \text { One-Level } & 35 & 95.9 \\ \text { Two-Level } & 19 & 4.1 \\ \text { Recurrences } & 11 & 2.2 \\ \text { Complications } & & 0.01\end{array}$

There was no measurable blood loss or serious complications such as postoperative bleeding or infection. There was one case of nerve root injury $(0.11 \%)$ in which the patient recovered well following physical therapy, and 11 cases of paresthesia that gradually improved following 2-6 weeks of rehabilitation and treatment with pregabalin. Postoperative pain medication was not required.

\section{Intraoperative findings}

40 (4\%) of the 857 patients had epidural adhesions, in spite of not having undergone prior microscopic surgery. The scar tissue was separated from the medial facet joint with the tip of the bevelled working channel using a gentle forward twisting motion under direct visualisation. The facet of medial soft tissue was cleaned and expanded with the help of RF.

In the transforaminal group, the superior articular process had to be drilled in seven cases (11\%). In the interlaminar group, in 250 cases (29\%) inferior articular process and the cranial lamina had to be partially resected. Technically, surgical removal of the herniated disc was possible in all cases. Intraoperative conversion to a conventional procedure was not required in any case (Fig. 4).

\section{Recurrent herniations}

There were 19 recurrences $(2.2 \%)$ during the follow-up period after a pain-free recovery stage; patients with those recurrences underwent the same operational technique as

Table 3. Herniation type: 1-level and 2-level

\begin{tabular}{lcc|}
\hline \multicolumn{1}{c}{ Herniation type } & 1-level & P value \\
\hline Extrusion & $400(48 \%)$ & $>0.05$ \\
Sequestration & $422(52 \%)$ & \\
& 2-level & \\
\hline Extrusion/Extrusion & $5(14.3 \%)$ & $<0.05$ \\
Sequestration/Sequestration & $3(8.6 \%)$ & \\
Extrusion/Sequestration & $9(25.7 \%)$ & \\
Sequestration/Extrusion & $18(51.4 \%)$ &
\end{tabular}

Table 2. General parameters of one-level and two-level groups

\begin{tabular}{|c|c|c|c|}
\hline General parameters & 1-Level & 2-Level & P value \\
\hline Age & $47.5 \pm 11.2$ & $46.1 \pm 12.1$ & $>0.05$ \\
\hline Mean operating time [mins] & $32.1 \pm 7.9$ & $57.7 \pm 5.1$ & $<0.05$ \\
\hline Mean length of hospital stay [days] & $15.8 \pm 2.2$ & $15.9 \pm 1.5$ & $>0.05$ \\
\hline Mean time to return to work [days] & $12.8 \pm 2.1$ & $18.4 \pm 1.9$ & $<0.05$ \\
\hline Scope shooting images & $7.91 \pm 1.5$ & $13.1 \pm 1.6$ & $<0.05$ \\
\hline Mean duration of symptoms [days] & $1.14 \pm 0.6$ & $1.4 \pm 0.5$ & $>0.05$ \\
\hline Complications & $11(1.3 \%)$ & $1(2.8 \%)$ & $<0.05$ \\
\hline Recurrences & $18(2.1 \%)$ & $1(2.8 \%)$ & $<0.05$ \\
\hline
\end{tabular}




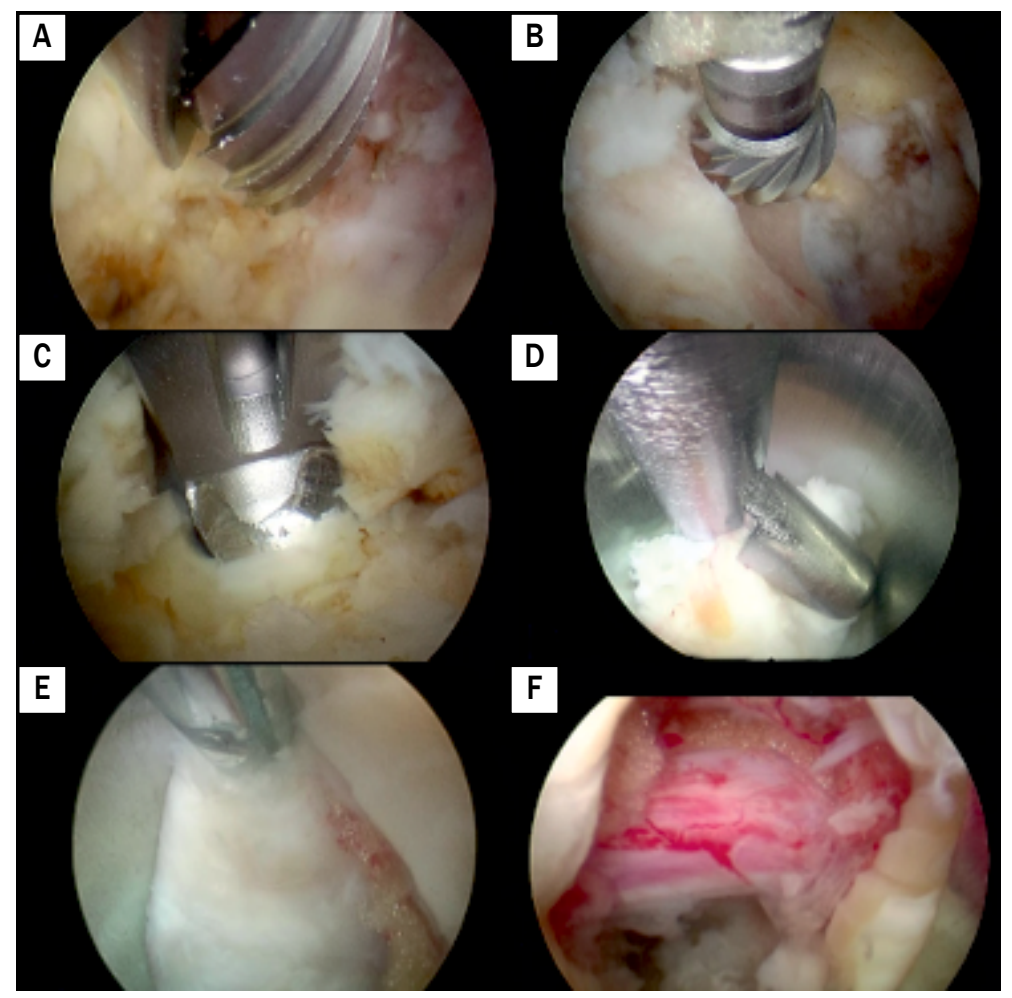

Figure 4. A-B. Drilling of mesial facet joint on endoscopic view; C. Releasing ligamantum flavum from bone with aid of RF; D. Removal of sequestered disc material with micropunch; E. Shrinking sequestered disc material with RF; F. View of relaxed root and defect after removal of sequestered disc material

the previous ones in the form of a revision surgery. Five of the patients had recurrence within the first 10 days. These patients had L5-S1 disc surgery and the annular defects were large. The other patients had recurrences after three and 12 months; most of these were L4-L5 disc with advanced age and degenerated, high distance disc including a patient with two-level disc disease. None of the patients underwent conventional revision. One patient underwent endoscopic revision surgery three times because of recurrence.

\section{Discussion}

Neuropathic pain originating from spinal disc herniations is a very common problem. Endoscopic spinal surgery has gained popularity because of its advantages such as minimal tissue trauma and faster recovery time after the surgery $[19,27]$.

Endoscopic techniques have shorter operating times, less blood loss, less incision pain, and faster postoperative rehabilitation/shorter hospital stay than microsurgical techniques. However, there have been no significant differences in the main clinical outcome criteria between endoscopic and microsurgical techniques in any of the trials [6]. Our study supported the findings in that a favourable clinical outcome was reached after endoscopic discectomy operation in a large group of patients.

To guarantee complete decompression, herniated discs usually have to be resected under visual control, even when a full-endoscopic technique is used. Therefore, the appropriate approach should be selected for each case individually. Overall, there were no differences found between the clinical outcomes of transforaminal and interlaminar approaches. Nonetheless, surgery involving transforaminal approaches may be associated with less trauma because the ligamentum flavum is not opened, leading to less recurrence as shown in our series.

Working space is increased by the possibility of bone resection and thus the surgical treatment of every disc herniation is technically possible. The new optics with the $4.2 \mathrm{~mm}$ intraendoscopic working channel and corresponding new instruments, shavers and burrs also expand the indication spectrum (for example, foraminal stenosis and recess stenosis). Parameters such as the osseous diameter of the interlaminar window or the extent of craniocaudally sequestering disc material are no longer contraindications to surgery. Likewise, the larger instruments enable removal of so-called hard-disc herniations and more efficient decompression of the intervertebral space $[15,24,26]$.

There are several reports claiming that muscle splitting during discectomy operations is associated closely with postoperative low back pain $[28,29]$. Minimally invasive techniques such as full-endoscopic spinal surgery has been proven to be less invasive compared to a conventional microdiscectomy procedure. It has been shown that, as a muscle 
injury indicator, creatine phosphokinase (CPK) levels are significantly lower in full-endoscopic disc surgery than conventional microdiscectomy [30]. Low CPK levels mean less tissue damage and less muscle injury. Also, the smaller incision site and less blood loss lead to less postoperative pain and a quicker recovery. Our study revealed that patients returned to work in less than 24 hours with acceptable reccurrence rates $(2.2 \%)$ and favourable pain control. This accords with the recent literature.

The main disadvantages of the procedure consist of a steep learning curve and possible complications. The learning curve for endoscopic techniques depends on several factors. A complete understanding of surgical anatomy must be thoroughly reviewed. Spinal anatomy, as well as associated surgical approach anatomy, should be reviewed. A fundamental experience of open and associated minimally invasive techniques is required. The surgeon should participate in multiple cadaveric sessions during which the major components of the surgical techniques are highlighted and performed.

Dural tears are a major problem for both conventional microdiscectomy and full-endoscopic discectomy procedures. We suggest that the low rate of cerebrospinal fluid fistula in our series is because of the experienced, and spinal surgery-oriented, team and the relatively narrow working field during full-endoscopic discectomy compared to microdiscectomy.

Another possible complication is adjacent abdominal structure injury due to malpositioning of the endoscopic canula which may cause infections such as abscess or spondylodiscitis [31]. In order to avoid intraabdominal injury, preoperative abdominal CT should be ordered to calculate the precise entry point during TF procedures.

Postoperative paresthesia is a common complication during TF procedures. In our series, all of the patients who had transient paresthesia underwent a TF approach. This complication is probably because of the limited movement of the canula in the large vertebral foramen causing root irritation during the procedure [32].

\section{Conclusions}

The results of this retrospective study show that sufficient decompression under direct visualisation with a relatively short operating time compared to conventional techniques is possible using the full-endoscopic transforaminal and interlaminar technique [18]. The full-endoscopic transforaminal and interlaminar discectomy procedure is a sufficient and safe supplement and alternative to conventional procedures $[21,22,33]$.

Conflict of interest: None.

Acknowledgement and financial support: None.

Authors' contributions: SA: (Concept, Design, Analysis and Interpretation of Data, Acquisition of Data, Drafting of Manuscript); EB: (Drafting of Manuscript, Statistical Analysis).

\section{References}

1. Yasargil MG, Vise WM, Bader DC. Technical adjuncts in neurosurgery. Surg Neurol. 1977; 8(5): 331-336, indexed in Pubmed: 918830.

2. Ebeling $\mathrm{U}$, Reichenberg $\mathrm{W}$, Reulen $\mathrm{HJ}$. Results of microsurgical lumbar discectomy. Review on 485 patients. Acta Neurochir (Wien). 1986; 81(12): 45-52, doi: 10.1007/bf01456264, indexed in Pubmed: 3728091.

3. Andrews DW, Lavyne MH. Retrospective analysis of microsurgical and standard lumbar discectomy. Spine (Phila Pa 1976). 1990; 15(4): 329-335, doi: 10.1097/00007632-199004000-00015, indexed in Pubmed: 2353279.

4. Alvi MA, Kerezoudis P, Wahood W, et al. Operative Approaches for Lumbar Disc Herniation: A Systematic Review and Multiple Treatment Meta-Analysis of Conventional and Minimally Invasive Surgeries. World Neurosurg. 2018; 114: 391-407.e2, doi: 10.1016/j. wneu.2018.02.156, indexed in Pubmed: 29548960.

5. Wu X, Zhuang S, Mao Z, et al. Microendoscopic discectomy for lumbar disc herniation: surgical technique and outcome in 873 consecutive cases. Spine (Phila Pa 1976). 2006; 31(23): 2689-2694, doi: 10.1097/01. brs.0000244615.43199.07, indexed in Pubmed: 17077737.

6. Ruetten $\mathrm{S}$, Komp M, Merk $\mathrm{H}$, et al. Recurrent lumbar disc herniation after conventional discectomy: a prospective, randomized study comparing full-endoscopic interlaminar and transforaminal versus microsurgical revision. J Spinal Disord Tech. 2009; 22(2): 122-129, doi: 10.1097/BSD.0b013e318175ddb4, indexed in Pubmed: 19342934.

7. Ruetten $\mathrm{S}, \mathrm{Komp} \mathrm{M}, \mathrm{Merk} \mathrm{H}$, et al. Use of newly developed instruments and endoscopes: full-endoscopic resection of lumbar disc herniations via the interlaminar and lateral transforaminal approach. J Neurosurg Spine. 2007; 6(6): 521-530, doi: 10.3171/spi.2007.6.6.2, indexed in Pubmed: 17561740.

8. Ruetten S. The Full-endoscopic Interlaminar Approach for Lumbar Disc Herniations. Minimally Invasive Spine Surgery. : 346-355, doi: 10.1007/3-540-29490-2_38.

9. Andersson GB, Brown MD, Dvorak J, et al. Consensus summary of the diagnosis and treatment of lumbar disc herniation. Spine (Phila Pa 1976). 1996; 21(24 Suppl): 75S-78S, doi: 10.1097/00007632199612151-00009, indexed in Pubmed: 9112328.

10. Annertz M, Jönsson B, Strömqvist B, et al. No relationship between epidural fibrosis and sciatica in the lumbar postdiscectomy syndrome. A study with contrast-enhanced magnetic resonance imaging in symptomatic and asymptomatic patients. Spine (Phila Pa 1976). 1995; 20(4): 449-453, doi: 10.1097/00007632-199502001-00007, indexed in Pubmed: 7747228.

11. Birkenmaier C, Komp M, Leu HF, et al. The current state of endoscopic disc surgery: review of controlled studies comparing full-endoscopic procedures for disc herniations to standard procedures. Pain Physician. 2013; 16(4): 335-344, indexed in Pubmed: 23877449.

12. Fairbank JC, Couper J, Davies JB, et al. The Oswestry low back pain disability questionnaire. Physiotherapy. 1980; 66(8): 271-273, indexed in Pubmed: 6450426.

13. Ahn Y, Lee SH, Park WM, et al. Percutaneous endoscopic lumbar discectomy for recurrent disc herniation: surgical technique, outcome, and prognostic factors of 43 consecutive cases. Spine (Phila Pa 1976). 2004; 29(16): E326-E332, doi: 10.1097/01. brs.0000134591.32462.98, indexed in Pubmed: 15303041.

14. de Divitiis E, Cappabianca P. Lumbar diskectomy with preservation of the ligamentum flavum. Surg Neurol. 2002; 58(1): 68; discussion 68-9, doi: 10.1016/s0090-3019(02)00755-3, indexed in Pubmed: 12361661. 
15. Ebara S, Harada T, Hosono N, et al. Intraoperative measurement of lumbar spinal instability. Spine (Phila Pa 1976). 1992; 17(3 Suppl): S44-S50, doi: 10.1097/00007632-199203001-00010, indexed in Pubmed: 1566184.

16. Gottlob C, Kopchok GE, Peng SK, et al. Holmium:YAG laser ablation of human intervertebral disc: preliminary evaluation. Lasers Surg Med. 1992; 12(1): 86-91, doi: 10.1002/Ism.1900120113, indexed in Pubmed: 1614268.

17. Mochida J, Toh E, Nomura T, et al. The risks and benefits of percutaneous nucleotomy for lumbar disc herniation. A 10-year longitudinal study. J Bone Joint Surg Br. 2001; 83(4): 501-505, doi: 10.1302/0301-620x.83b4.11508, indexed in Pubmed: 11380118.

18. Oertel JM, Burkhardt BW. Endoscopic Intralaminar Approach for the Treatment of Lumbar Disc Herniation. World Neurosurg. 2017; 103: 410418, doi: 10.1016/j.wneu.2017.03.132, indexed in Pubmed: 28391024.

19. Markovic M, Zivkovic N, Spaic M, et al. Full-endoscopic interlaminar operations in lumbar compressive lesions surgery: prospective study of 350 patients. "Endos" study. J Neurosurg Sci. 2016; 30, indexed in Pubmed: 27362665.

20. Ruetten S, Komp M, Godolias G. An extreme lateral access for the surgery of lumbar disc herniations inside the spinal canal using the full-endoscopic uniportal transforaminal approach-technique and prospective results of 463 patients. Spine (Phila Pa 1976). 2005; 30(22): 2570-2578, doi: 10.1097/01.brs.0000186327.21435.cc, indexed in Pubmed: 16284597.

21. Destandau J. A special device for endoscopic surgery of lumbar disc herniation. Neurol Res. 1999; 21(1): 39-42, doi: 10.1080/01616412.1999.11740889, indexed in Pubmed: 10048052.

22. Goald HJ. Microlumbar discectomy: follow-up of 477 patients. J Microsurg. 1980; 2(2): 95-100, doi: 10.1002/micr.1920020204, indexed in Pubmed: 7217885.

23. Donceel $\mathrm{P}$, Du Bois M. Fitness for work after surgery for lumbar disc herniation: a retrospective study. Eur Spine J. 1998; 7(1): 29-35, doi: 10.1007/s005860050023, indexed in Pubmed: 9548355.

24. Ruetten S, Komp M, Godolias G. A New full-endoscopic technique for the interlaminar operation of lumbar disc herniations using 6-mm endoscopes: prospective 2-year results of 331 patients. Minim Invasive Neurosurg. 2006; 49(2): 80-87, doi: 10.1055/s-2006-932172, indexed in Pubmed: 16708336.
25. McCulloch JA. Focus issue on lumbar disc herniation: macro- and microdiscectomy. Spine (Phila Pa 1976). 1996; 21(24 Suppl): 45S-56S, doi: 10.1097/00007632-199612151-00005, indexed in Pubmed: 9112324.

26. Phan K, Xu J, Schultz K, et al. Full-endoscopic versus micro-endoscopic and open discectomy: A systematic review and meta-analysis of outcomes and complications. Clin Neurol Neurosurg. 2017; 154: 1-12, doi: 10.1016/j.clineuro.2017.01.003, indexed in Pubmed: 28086154.

27. Butler AJ, Alam M, Wiley K, et al. Endoscopic Lumbar Surgery: The State of the Art in 2019. Neurospine. 2019; 16(1): 15-23, doi: 10.14245/ns.1938040.020, indexed in Pubmed: 30943703.

28. Kawaguchi Y, Matsui H, Tsuji H. Back muscle injury after posterior lumbar spine surgery. A histologic and enzymatic analysis. Spine (Phila Pa 1976). 1996; 21(8): 941-944, doi: 10.1097/00007632-19960415000007, indexed in Pubmed: 8726197.

29. Kotil K, Tunckale T, Tatar Z, et al. Serum creatine phosphokinase activity and histological changes in the multifidus muscle: a prospective randomized controlled comparative study of discectomy with or without retraction. J Neurosurg Spine. 2007; 6(2): 121-125, doi: 10.3171/spi.2007.6.2.121, indexed in Pubmed: 17330578.

30. Pan L, Zhang P, Yin Q. Comparison of tissue damages caused by endoscopic lumbar discectomy and traditional lumbar discectomy: a randomised controlled trial. Int J Surg. 2014; 12(5): 534-537, doi: 10.1016/j.jisu.2014.02.015, indexed in Pubmed: 24583364.

31. Kim WJ, Lim ST, Lee SH. Pyogenic psoas abscess and secondary spondylodiscitis as a rare complication of percutaneous endoscopic lumbar discectomy: a case report. Joint Diseases and Related Surgery. 2005; 16: 163-166.

32. Sencer A, Yorukoglu AG, Akcakaya MO, et al. Fully endoscopic interlaminar and transforaminal lumbar discectomy: short-term clinical results of 163 surgically treated patients. World Neurosurg. 2014; 82(5): 884-890, doi: 10.1016/j.wneu.2014.05.032, indexed in Pubmed: 24907438.

33. Jang JS, An SH, Lee SH. Transforaminal percutaneous endoscopic discectomy in the treatment of foraminal and extraforaminal lumbar disc herniations. J Spinal Disord Tech. 2006; 19(5): 338-343, doi: 10.1097/01.bsd.0000204500.14719.2e, indexed in Pubmed: 16826005. 